\title{
Análisis de Juntas Adhesivas Elaboradas con (Lámina de Madera Plástica) / (Adhesivo Ecológico) / (Lámina de Madera Plástica)
}

\author{
Oscar Y. Buitrago, Arnoldo E. Delgado y Pedro J. Rodríguez \\ Facultad de Ingeniería. Universidad Militar Nueva Granada, carrera 11 No. 101-80. Bogotá-Colombia. \\ (e-mail: oscar.buitrago@unimilitar.edu.co)
}

${ }^{*}$ Autor a quien debe dirigirse la correspondencia

Recibido Ago. 31, 2016; Aceptado Nov. 14, 2016; Versión final Dic. 22, 2016, Publicado Abr. 2017

\begin{abstract}
Resumen
Se realizó un estudio experimental para medir la fuerza adhesiva de dos láminas de composición similar unidas con adhesivo. Las láminas se fabricaron a partir de polietileno con $32 \%$ de harina Telinne monspessulana y $5,2 \%$ de polietileno maleatado. Se usaron dos tipos de adhesivos ecológicos: poliuretano en dispersión acuosa y goma caliente de etilen vinil acetato (hot melt). Los substratos o superficies a unir de cada lámina previamente fueron sometidos a abrasión mecánica. Posteriormente las superficies fueron tratadas por separado con silano vinil-tri(2-metoxi etoxi), primer acrílico y diisocianato. La resistencia a la separación de ambos substratos denominada fuerza adhesiva de la junta, fue determinada aplicando la prueba $180^{\circ}$ T-peel adhesión. Los tratamientos químicos aumentaron la resistencia adhesiva de las juntas unidas con poliuretano, los valores más altos se obtuvieron al unir los substratos con adhesivo hot melt sin tratamiento químico. La adición de agente maleatado en el compuesto de madera plástica no mejoró la eficiencia de los tratamientos químicos.
\end{abstract}

Palabras clave: madera plástica; junta adhesiva; polietileno de baja densidad; peel adhesión; primer, adhesivo.

\section{Analysis of Bonded Joints Made with (Wood Plastic Composite Sheet) / (Ecological Adhesive) / (Wood Plastic Composite Sheet)}

\begin{abstract}
An experimental study was performed to measure the resistance to adhesive peel strength of two sheets of similar composition bonded with adhesive. The sheets were made from polyethylene with $32 \%$ Telinne monspessulana flour and $5.2 \%$ maleated polyethylene. Two types of eco-friendly adhesives were used: aqueous dispersion polyurethane and hot melt ethylene vinyl acetate base. The substrates or surfaces to be bonded from each sheet previously were subjected to mechanical abrasion. Subsequently the surface was treated with vinyl tri (2 -methoxyethoxy) silane, acrylic and diisocyanate primers. The resistance to the separation of both substrates also named as adhesive force of the joint, was determined with the test $180^{\circ}$ T-peel adhesión. Chemical treatments increased the peeling strength in the bonded joints with polyurethane water-based, however higher values were obtained by joining the substrates with hot melt adhesive without chemical treatment. The addition of maleate in the wood plastic composite did not improve the efficiency of chemical treatments.
\end{abstract}

Keywords: wood plastic composite; joint adhesive; low density polyethylene; peel adhesión; primer, adhesive. 


\section{INTRODUCCIÓN}

Variedad de productos como perfiles, vallas, tableros, laminas extruidas para la industria de la construcción, automotriz, hogar, decoración y juguetería son elaborados a partir de compuestos formulados con plástico y madera-wood plastic composites (WPC). Estos materiales ofrecen ventajas sobre los compuestos tradicionales (polímero/carga mineral), tales como alta resistencia y módulo, baja densidad, menor desgaste abrasivo en la maquinaria de proceso (Gardner et al., 2015; Gupta et al., 2007; Kim y Pal, 2010; Oporto et al., 2007). Con respecto a la madera, WPC tienen mejor estabilidad dimensional en condiciones de humedad, mayor resistencia térmica y al ataque microbiano. Desde el punto de vista ambiental los WPC de carácter termoplástico permiten incorporar plástico y residuos de madera reciclados, de hecho en algunas aplicaciones WPC están reemplazando parcialmente la madera. Los productos livianos permiten ahorro de energía en el transporte (Haftkhani et al., 2011).

En determinadas aplicaciones se requiere que los WPC tengan además la capacidad de formar uniones adhesivas con otros materiales, bien sea de forma temporal o definitiva, por ejemplo en estructuras laminares tipo multicapa en la industria automotriz, accesorios para calzado y hogar. La mayoría de WPC se fabrican a partir de poliolefinas económicas como polipropileno (PP), polietileno (PE), lo cual implica que su capacidad para formar uniones adhesivas sea muy difícil debido a que estos polímeros poseen la más baja energía superficial, por ejemplo la energía superficial del PE es $0,031 \mathrm{~mJ} / \mathrm{m}^{2}$ (Adderley et al., 1988).

El término substrato hace referencia a la superficie que es impregnada con adhesivo para formar una unión adhesiva. Prácticamente todos los WPC elaborados con poliolefinas requieren de tratamientos superficiales previos a la fijación de adhesivo, entre ellos se mencionan aplicación de ácido nítrico, acido crómico, permanganato de potasio, peroxidisulfato de amonio, flúor, peróxidos, sustancias cloradas y cromo hexavalente, este último solo se usa en ciertas condiciones y de manera limitada porque es una sustancia peligrosa para la salud y el medio ambiente (Critchlow, 2011; Davis, 2011). Dimitriou y colaboradores por ejemplo trataron la superficie de un WPC elaborado con PP y harina de abeto usando peróxido de hidrógeno, logrando un incremento de la fuerza adhesiva de 36,4\% (750 N) (Dimitriou et al., 2016). Los tratamientos de oxidación de la superficie por medio de gases ionizados como descarga de corona, plasma a baja presión y plasma son los más comunes en la actualidad (Moghadamzadeh et al., 2011; Oporto et el., 2010)

Otra manera para aumentar la energía superficial y por ende la capacidad del substrato para formar uniones adhesivas es mediante la fijación sobre la superficie de sustancias con grupos funcionales o injertos de monómeros polares. Usualmente estas sustancias se aplican en forma de primers. En la industria de los adhesivos la palabra primer está referida a sustancias reactivas (silanos, isocianatos, derivados acrílicos) que están disueltas en solventes orgánicos, y que se aplican sobre la superficie usando brocha, spray; el solvente se evapora y las moléculas reactivas actúan formando enlace entre el adhesivo y el substrato ( Abel, 2011).

En la literatura se encuentra información detallada sobre el uso de silanos para mejorar la compatibilidad de fibras naturales y polímeros. Con el fin de aumentar la resistencia mecánica. En la industria de adhesivos, los silanos se usan como promotores de adhesión (agentes de entrecruzamiento/endurecedores), en la práctica los adhesivos son mezclados con pequeñas proporciones (3-6\%) de silano antes de la aplicación sobre el substrato, esto se hace para impartirle al adhesivo resistencia térmica y mecánica (Abel 2011). De otro lado estas moléculas también funcionan como primers, cuando se depositan sobre el substrato formando una delgada película, la cual provee de grupos funcionales la superficie aumentando la polaridad del substrato (en otras palabras mejorando la capacidad para formar uniones adhesivas).

En general se acostumbra a realizar un tratamiento mecánico sobre la superficie del substrato con el fin de aumentar su rugosidad por medio de abrasión antes de aplicar primers o gases ionizantes. En WPC, la abrasión promueve la exposición de las fibras naturales favoreciendo el anclaje de grupos funcionales provenientes de primers (Gupta et al., 2007).

La unión adhesiva de substratos WPC con adhesivos ecológicos son la alternativa al uso de cementos base solvente (en extremo peligrosos para la salud). La unión de substratos WPC con adhesivos hot melt, es la más común en cuanto al uso de adherentes de bajo contenido de volátiles orgánicos (VOC por sus siglas en ingles). Los hot melt son mezclas de polímero (etileno vinil acetato, poliamidas, poliésteres) con resinas tactificantes y extendedores, $100 \%$ sólidos. La característica importante es la humectación con el substrato que solo se logra en pocos segundos si el adhesivo se aplica en estado fundido. Se usan para pegar piezas livianas, proporcionan pegajosidad y alta resistencia térmica con relativa alta fuerza adhesiva. La principal desventaja es la disminución de la resistencia de la junta adhesiva con el incremento de la temperatura (Papon, 2011). 
Otra categoría ambientalmente amigable con potencial aplicación en WPC son los adhesivos en dispersión acuosa, los cuales son producidos por polimerización en emulsión. Tienen ventajas como alto contenido de sólidos, flexibilidad, buen comportamiento a baja temperatura, la viscosidad no depende del peso molecular, baja toxicidad, menor riesgo en el almacenamiento y aplicación, poseen buena adhesión. Dentro de la gama se encuentran dispersiones de copolímeros de acetato de vinilo con acrilatos, base poliuretano y cloropreno entre otros. Es imperativo tratar superficialmente los substratos con abrasión, uso de primers o gases ionizantes con el fin de garantizar un adecuado anclaje de la película adherente.

Los adhesivos en dispersión acuosa requieren del mejoramiento de la resistencia a la temperatura, disminución de la sensibilidad a la humedad, aumento de la fuerza cohesiva de la unión e incremento de la adhesión. Para lograr estos propósitos se deben usar junto al adhesivo un segundo componente llamado endurecedor (agente de entrecruzamiento), el cual se mezcla con el adhesivo antes de ser aplicado sobre el substrato (Humar et al., 2011; Lei et al., 2015; Mulonda et al., 2011; Oporto et al., 2007; Rahman et al., 2008).

En esta investigación se usó harina vegetal obtenida del arbusto leñoso Telinne monspessulana; especie proveniente del mediterráneo e invasora de la zona andina colombiana donde se le conoce con el nombre de retamo liso. La harina natural fue mezclada con polietileno de baja densidad y se adicionó un agente de acoplamiento tipo copolímero maleatado. El compuesto resultante de la mezcla fue prensado en caliente para obtener las láminas y a partir de estas se elaboraron las probetas (substratos), la unión de dos probetas por medio de adhesivo se denomina junta adhesiva. Las superficies de los substratos con previa abrasión mecánica fueron tratadas de manera distinta aplicando por separado tres primers, uno acrílico, otro preparado en el laboratorio de tipo diisocianato y un tercero elaborado a partir de la hidrólisis del vinil-tri(2metoxi etoxi)silano-VTMS. La aplicación de estos agentes sobre los substratos se hizo para mejorar la capacidad de adhesión. Se usaron dos tipos de adhesivos ecológicos: dispersión acuosa de poliuretano y adhesivo de fusión en caliente (hot melt) a base etileno vinil acetato-EVA. Las juntas fueron sometidas a ensayos de 180ㅜ-Peel adhesión con el fin de evaluar la calidad de los tratamientos químicos, la influencia del agente de acoplamiento y el tipo de adhesivo.

\section{METODOLOGÍA}

Se describe la elaboración del WPC y de las juntas adhesivas con substratos WPC. Luego se explica cómo se realizan los tratamientos superficiales y la aplicación de adhesivos para terminar con detalles del ensayo de resistencia al pelado y del diseño experimental

\section{Elaboración del WPC}

El compuesto fue elaborado siguiendo el procedimiento descrito por (Palacio et al., 2016). Los ingredientes se mezclaron en un equipo de cámara interna tipo Brabender Plastic Corder, posteriormente se obtuvieron láminas mediante moldeo por compresión.

Tabla 1: Formulaciones WPC

\begin{tabular}{|c|c|c|c|c|}
\hline Componentes WPC & Fórmula $A$ & Fórmula $B$ & Referencia & Propiedades \\
\hline $\begin{array}{l}\text { Polietileno de baja } \\
\text { densidad }\end{array}$ & 100 & 100 & Polifen $^{\circledR} 641$ (Ecopetrol ${ }^{\mathrm{TM}}$ ) & MFI: 1,7-2,3 g/10 min; \\
\hline Harina de madera & 50 & 50 & Telinne monspessulana & $\phi=400-800 \mu \mathrm{m} ; \mathrm{h}=0,20 \%$ \\
\hline Ayuda de Proceso & 1,0 & 1,0 & Struktol ${ }^{\circledR}$ WB16 (Struktol ${ }^{\mathrm{TM}}$ Inc) & - \\
\hline Antioxidante & 1,0 & 1,0 & Irganox ${ }^{\circledR} 1076\left(\right.$ Basf $\left.^{\mathrm{TM}}\right)$ & - \\
\hline Resina tactificante & 2,5 & 2,5 & Unilene $^{\circledR}$ A100 (Basile Quimica ${ }^{\mathrm{TM}}$ ) & TABLANDAMIENTO: $98^{\circ} \mathrm{C}$ \\
\hline $\begin{array}{l}\text { Agente de } \\
\text { acoplamiento }\end{array}$ & & 8,0 & MAPE (Hangzhou Uniwise ${ }^{\mathrm{TM}}$ ) & Rate graft $0,9 \rho: 0,95 \mathrm{~g} / \mathrm{cm}^{3}$ \\
\hline
\end{tabular}

Se elaboraron dos (2) tipos de WPC, sin agente de acoplamiento (formula A) y con 4,9 \% de MAPE (fórmula B), con el fin de analizar su influencia en la unión adhesiva, según se observa en la Tabla 1. En adelante se usarán las palabras substrato $A$ y substrato $B$ para hacer referencia a los compuestos elaborados con las formulas $A$ y $B$ respectivamente. En términos de adhesión, substratos son los materiales que se impregnan de adhesivo para formar unión adhesiva (junta). 


\section{Elaboración juntas adhesivas con substratos WPC}

Las probetas para la determinación de la resistencia al pelado se obtuvieron por troquelado las láminas de WPC con dimensiones de $15 \mathrm{~cm}$ largo; $2,54 \mathrm{~cm}$ de ancho, espesor: 3,18 mm.

\section{Tratamientos superficiales}

Tratamiento mecánico: Todas las probetas independientemente del tipo de tratamiento químico o del adhesivo aplicado se sometieron a una abrasión manual usando una lija grano A-180 de zirconio, para aumentar la rugosidad superficial. Primers: Se fijaron sobre la superficie raspada o lijada de los substratos utilizando una brocha de cerdas de nailon, el tiempo de aplicación fue 15 segundos. Como referencia se usó un Primer $94^{\circledR}$ el cual según la especificación técnica es recomendable para adherir polietileno. El primer basado en toluen diisocianato se preparó en el laboratorio usando el vulcanizante AQ212 ${ }^{\circledR}$ (ver Tabla 2).

Tabla 2: Tratamiento químico superficial

\begin{tabular}{|c|c|c|c|}
\hline Trat. químico & Composición & Referencia & Modo de aplicación \\
\hline $\begin{array}{l}\text { Primer Acrílico } \\
\text { (Referencia) }\end{array}$ & $\begin{array}{l}\text { Acrílicos, resinas } \\
\text { tactificantes }\end{array}$ & Primer $94^{\circledR}$ fabricado por $3 \mathrm{M}^{\mathrm{TM}}$ & \multirow{2}{*}{$\begin{array}{l}\text { Aplicación con brocha sobre } \\
\text { cada uno de los substratos. } \\
\text { Secado a } 22^{\circ} \mathrm{C}\end{array}$} \\
\hline Primer TDI & $\begin{array}{l}\text { TDI }(5,5 \%)+\text { MEK }(94,5 \%) \\
\text { Nota: Preparado en el lab. }\end{array}$ & $\begin{array}{l}\text { TDI: Vulcanizante } A Q 212^{\circledR} \\
\text { MEK: Metil etil cetona }\left(\text { Shell }{ }^{\mathrm{TM}}\right)\end{array}$ & \\
\hline Silano VTMS & $\begin{array}{l}\text { VTMS/ } / \mathrm{H}_{2} 0 / \text { Etanol } \\
\text { Nota: Preparado en el lab. }\end{array}$ & $\begin{array}{l}\text { VTMS: SCA } 972^{\circledR}\left(\text { Struktol }{ }^{\mathrm{TM}} \text { Inc) }\right. \\
\mathrm{H}_{2} \mathrm{O} \text { : desionizada, etanol al } 96 \%\end{array}$ & (Ver procedimiento) \\
\hline
\end{tabular}

Tratamiento con silano VTMS: Inicialmente se realizó pre-hidrólisis del silano disolviéndolo en $80 \%$ de solución acuosa de etanol durante una (1) hora a 25으, el pH se ajustó a 3,2-3,5 con ácido acético glacial. En seguida se aplicó la solución hidrolizada sobre la superficie raspada de los substratos, se mantuvo en estas condiciones por 4 horas a $25^{\circ} \mathrm{C}$, finalmente los substratos fueron secados en un horno a $55^{\circ} \mathrm{C}$ durante $24 \mathrm{~h}$, las probetas quedaron así listas para el pegado con adhesivo base agua.

\section{Aplicación de adhesivos}

Adhesivo poliuretano en suspensión acuosa: Se preparó la mezcla Hidropul $500^{\circledR}$ con vulcanizante AQ212 ${ }^{\circledR}$ ( $3 \%$ en peso). A continuación se fijaron dos capas de adhesivo con intervalo de 15 minutos entre aplicación, se utilizó una brocha de cerdas suaves. Las probetas fueron llevadas a un horno durante 10 minutos a $60{ }^{\circ} \mathrm{C}$ para acelerar el proceso de formación de película después de cada aplicación (ver Tabla 3 y Figura 1 a-b). La junta adhesiva se hizo tomando dos probetas de substrato de similar formulación, luego fueron llevadas a un horno a $120 \stackrel{\circ}{ } \mathrm{C}$ durante 90 segundos, enseguida se unieron manualmente las superficies que tenían la película de adhesivo, finalmente la junta se colocó sobre una prensa hidráulica donde se aplicó presión de $36 \mathrm{kgf} / \mathrm{cm}^{2}$ durante 10 segundos.

Tabla 3: Adhesivos

\begin{tabular}{|c|l|l|l|}
\hline \multicolumn{1}{|c|}{ Adhesivo } & \multicolumn{1}{|c|}{ Propiedades/Composición } & Referencia & \multicolumn{1}{c|}{ Tratamiento químico } \\
\hline $\begin{array}{c}\text { Dispersión acuosa } \\
\text { de poliuretano }\end{array}$ & $\begin{array}{l}\text { Viscosidad: } 5100 \mathrm{cps} \text {; sólidos: } 48,4 \% . \\
\text { Fuerza adhesiva: }>8,5 \mathrm{kN} / \mathrm{m}\end{array}$ & Hidropul $500^{\circledR}$ & $\begin{array}{l}\text { Se aplicó sobre substratos A y B con } \\
\text { aplicación previa de primers y silano } \\
\text { VTMS }\end{array}$ \\
\hline Hot melt & $\begin{array}{l}\text { EVA (20-40\%); polímero (20-40\%) } \\
\text { ceras (20-30\%); } \\
\text { Resina de hidrocarburo (5-10\%) }\end{array}$ & $\begin{array}{l}\text { Pegadit }{ }^{\circledR} \\
\text { aplicó en superficies todo raspad }\end{array}$ \\
\hline
\end{tabular}

Aplicación de hot melt: Las probetas fueron calentadas en el horno a $120{ }^{\circ} \mathrm{C}$ durante 5 minutos aprox., con el fin de garantizar la aplicación en forma de película del hot melt. Cuando las probetas alcanzaron $100 \stackrel{\circ}{ } \mathrm{C}$ en la superficie, se impregnaron con adhesivo usando un aplicador hot melt (pistola), enseguida el adhesivo se esparció sobre la superficie con la ayuda de un cilindro de acero inoxidable con diámetro $1,5 \mathrm{~cm}$ y largo $10 \mathrm{~cm}$, de esta manera se logró formar una película adhesiva. Posteriormente las probetas fueron llevadas nuevamente al horno durante 2 minutos con el fin de garantizar la fusión del hot melt, al final del proceso los substratos de similar formulación se unen formando la junta que luego se lleva a la prensa aplicando 36 $\mathrm{kgf} / \mathrm{cm}^{2}$ de presión durante 10 segundos. 


\section{Ensayo de resistencia al pelado (180 T-Peel adhesión)}

Mide la fuerza requerida para desprender los substratos que forman la junta, la fuerza se aplica sobre los substratos formando Angulo de $180^{\circ}$ según se observa en la figura 1-c).
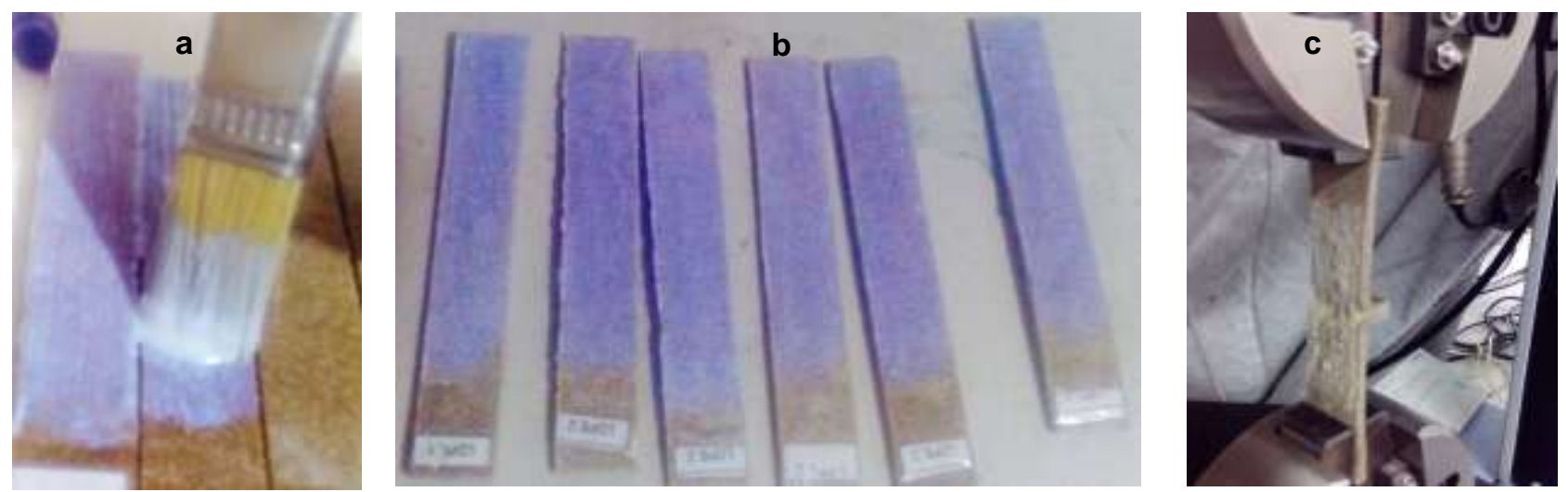

Fig. 1: a y b) Aplicación de PU en dispersión acuosa sobre substratos de WPC; c) Prueba 180ํT-peel adhesión

Es usual presentar el resultado de la prueba como un promedio de la fuerza por unidad de longitud de la probeta. Es una prueba importante en la producción industrial, tiene la ventaja de ser un método aparentemente simple y practico de análisis, el cual no tiene en cuenta conceptos como energía de adhesión, espesor de la capa de adhesivo (Kinloch y Williams 2002). La prueba se realizó siguiendo la norma ASTM C794-15A, se usó la máquina universal de ensayos Shimadzu® AGS-X. Parámetros: velocidad de desplazamiento: $50 \mathrm{~mm} /$ minuto, temperatura $24^{\circ} \mathrm{C}$, humedad relativa $54 \%$. Se usaron dos (2) juntas adhesivas por ensayo, las probetas permanecieron en reposo dos semanas desde la elaboración de la junta hasta la fecha del ensayo peel.

\section{Diseño experimental}

La prueba de resistencia al pelado fue analizada partiendo de un diseño experimental completamente al azar de un factor y diez niveles (MAPE, tratamiento químico, adhesivo). Por medio del análisis ANOVA de una vía se determinaron los efectos significativos del tratamiento químico, tipo de adhesivo y presencia de agente de acoplamiento maleatado sobre la variable de respuesta (peel adhesión) con nivel de confianza del $95 \%$. Se reitera que el adhesivo hot melt se aplicó a los substratos que no tuvieron tratamiento químico y que todas las juntas se hicieron con substratos de igual formula (A ó B).

\section{RESULTADOS Y DISCUSIÓN}

El análisis estadístico aplicando ANOVA de una vía, arroja diferencias significativas en cuanto al tipo de adhesivo aplicado, tratamiento químico y la presencia de agente de acoplamiento polietileno maleatado según se observa en las Tablas 4 y 5 . No es fácil dilucidar el mecanismo de adhesión en superficies tipo WPC que han sido raspadas usando papel abrasivo, hay varios factores que influyen en la capacidad del substrato para formar unión adhesiva, por ejemplo, compuestos de polietileno con alto porcentaje de harina de madera (> $70 \%$ ) poseen una superficie más hidrofílica o polar, mientras que si el porcentaje es menor al $20 \%$ la superficie estará influenciada por el carácter hidrófobo y apolar de la poliolefina, haciendo al substrato más difícil de adherir.

Tabla 4: 180 T-Peel Adhesión. Substrato A (WPC sin MAPE); Substrato B (WPC con 8 phr MAPE)

\begin{tabular}{|c|c|c|c|c|}
\hline \multirow{2}{*}{ Junta Adhesiva } & $\begin{array}{c}\text { Tratamiento } \\
\text { Químico Superficial }\end{array}$ & $\begin{array}{c}N^{\circ} \text { de } \\
\text { Observaciones }\end{array}$ & $\begin{array}{c}\text { Incremento de } \\
\text { Peel adhesión }\end{array}$ & $\begin{array}{c}\text { Variación vs } \\
\text { Control }\end{array}$ \\
\hline \multirow{3}{*}{ Substrato A / adhesivo PU / Substrato A } & Ninguno (Control) & 200 & - & - \\
\cline { 2 - 5 } & Primer SCA & 200 & $+49,7 \%$ & Significativa \\
\cline { 2 - 5 } & Primer Acrílico & 200 & $+48,9 \%$ & Significativa \\
\cline { 2 - 5 } & Primer TDI & 200 & $+24,7 \%$ & Significativa \\
\cline { 2 - 5 } & Ninguno & 200 & $+120,1 \%$ & Significativa \\
\hline Substrato A / Hot melt / Substrato A & Ninguno & 200 & $-4,0 \%$ & No significativa \\
\hline \multirow{3}{*}{ Substrato B / adhesivo PU / Substrato B } & Primer SCA & 200 & $+8,7 \%$ & No significativa \\
\cline { 2 - 5 } & Primer Acrílico & 200 & $+17,5 \%$ & Significativa \\
\cline { 2 - 5 } & Primer TDI & 200 & $-6,4 \%$ & No significativa \\
\hline Substrato B / Hot melt / Substrato B & Ninguno & 200 & $+130,1 \%$ & Significativa \\
\hline
\end{tabular}


Tabla 5: ANOVA 180T-Peel Adhesión

\begin{tabular}{|l|c|c|c|c|c|}
\hline \multicolumn{1}{|c|}{ Origen de la variación } & $\Sigma \Sigma$ & $\varrho L$ & $M S$ & $p$ & $F$ \\
\hline Entre grupos & 269951135 & 9 & 29994570,6 & 0,0000 & 19761 \\
\hline Dentro de grupos & 3020579 & 1990 & 1517,88 & & \\
\hline Total & 272971714 & 1999 & & & \\
\hline
\end{tabular}

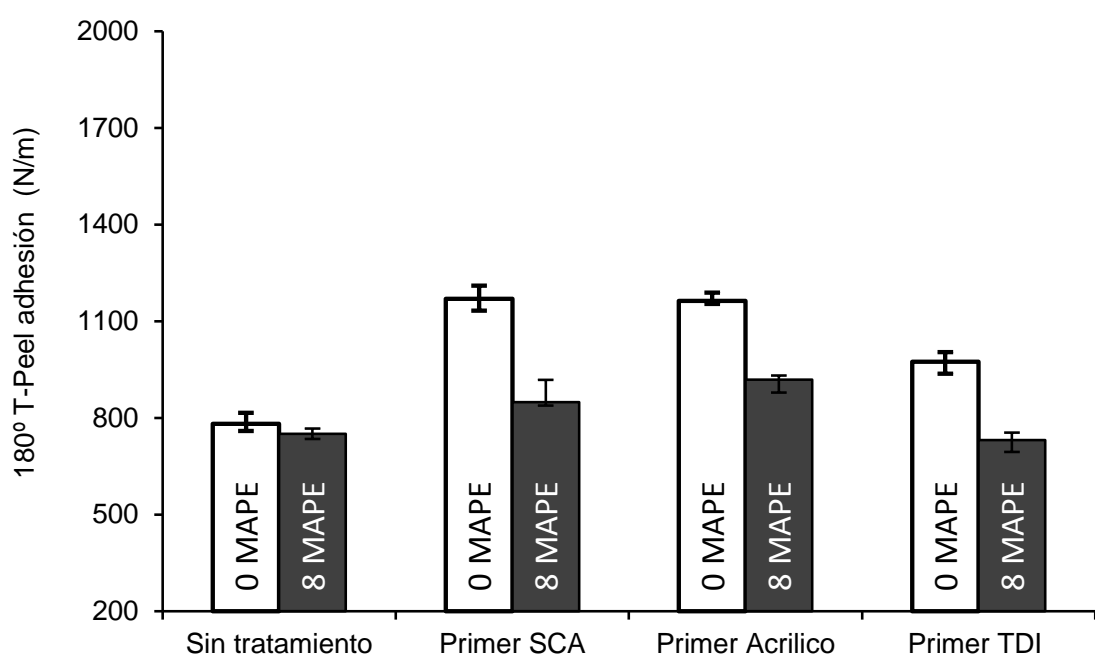

Adhesivo poliuretano base agua. Substratos tratados

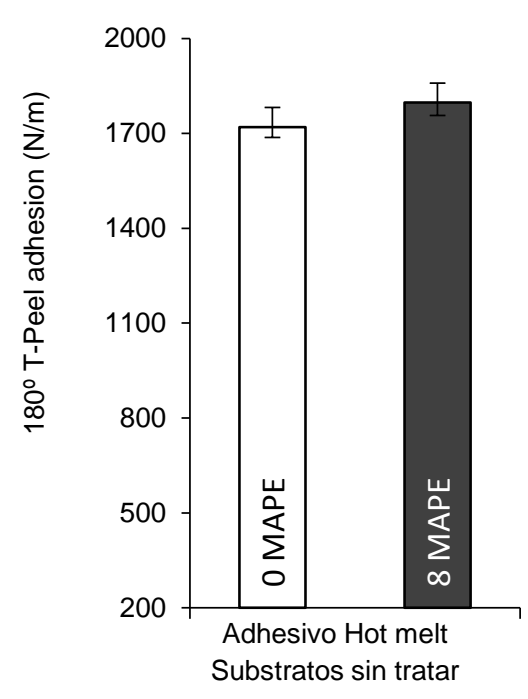

Fig. 2: Resultados de la Prueba 180ำ T-Peel Adhesión

De otro lado, los aditivos que hacen parte del compuesto como lubricantes, ceras con el tiempo migran hacia la superficie ayudando a incrementar la complejidad del mecanismo de adhesión (Gardner et al., 2015). En esta investigación se elaboraran juntas adhesivas a partir de substratos tipo WPC elaborados con polietileno de baja densidad y $32 \%$ en peso de harina de madera del arbusto Telinne monspessulana.

\section{WPC formulado con polietileno maleatado vs 180 T-Peel adhesión:}

Agente de acoplamiento MAPE fue adicionado al WPC durante la etapa de mezclado, los substratos denominados con la letra B contienen 8 phr del agente (ver Tabla 1). Los agentes de acoplamiento tipo copolimeros de maleato han sido ampliamente usados para mejorar propiedades mecánicas de WPC (Palacio et al., 2016). Desde luego en este estudio se analizó su influencia sobre la propiedad adhesiva resistencia al pelado en substratos sometidos a abrasión (lijado) y posterior tratamiento químico.

Al observar la Tabla 4 y la Figura 2 se aprecia que la incorporación del agente MAPE no mejoró la capacidad del substrato para formar unión adhesiva, por el contrario afectó negativamente cuando hubo tratamiento químico previo a la aplicación del adhesivo de poliuretano base agua. Cuando se cambió el adhesivo por uno de tipo Hot melt, no se halló diferencia significativa por la presencia de MAPE ya que el adhesivo termo fundente interactúa con la poliolefina dada su afinidad química.

En las superficies que han sido sometidas a abrasión, la incorporación de MAPE hace que las grupos hidrófilos de la harina de madera no queden expuestos porque han sido acoplados con el agente, en otras palabras la superficie adquiere menor energía superficial como resultado del acoplamiento fibra-polímero lo cual favorece el aumento de las propiedades mecánicas en detrimento de la capacidad del substrato para formar uniones adhesivas. Como tal, la interacción de los grupos funcionales de los primers no pueden actuar sobre la partícula de madera porque estos no están disponibles ya que han sido previamente acoplados con MAPE, los primers que han sido analizados difícilmente modifican la polaridad de substratos tan difíciles de unir como el polietileno.

Este resultado concuerda con la investigación realizada por (Gupta et al. 2007), quienes elaboraron un compuesto de polietileno de alta densidad con $60 \%$ de harina de pino y le añadieron agente de acoplamiento polipropileno maleatado MAPP, la resistencia al pelado del compuesto sin MAPP es $218 \pm 16$ $\mathrm{N} / \mathrm{m}$ y con $2,3 \%$ de MAPP fue $177 \pm 21 \mathrm{~N} / \mathrm{m}$. En la misma investigación se evaluó la resistencia al pelado de compuesto elaborado con polipropileno y $60 \%$ de harina de pino, la resistencia al pelado del WPC sin MAPP fue es $290 \pm 24 \mathrm{~N} / \mathrm{m}$ y con 2,3\% de MAPP fue $232 \pm 9 \mathrm{~N} / \mathrm{m}$; en ambos casos se usó adhesivo acrílico base agua y hubo un tratamiento previo de abrasión. 
Para lograr mejorar la adhesión de substratos que tienen agentes de acoplamiento de tipo maleato, en uniones adhesivas aplicando adhesivos de PU en dispersión acuosa es imperativo la aplicación de tratamientos combinados entre químicos y oxidativos, como por ejemplo descarga de corona, plasma a baja presión debido a que estos si actúan sobre el polímero. Por ejemplo, en un estudio publicado por Yáñez y Martínez se indica que tratamiento con plasma a baja presión incrementó la resistencia al pelado en $230 \%$ para substratos elaborados con polietileno y 25\% de harina de madera (Yáñez y Martín, 2012)

\section{Efecto del tratamiento químico- adhesión con poliuretano base agua}

Anteriormente se mencionó que los primers actúan de manera más determinante en aquellos substratos que no tienen agente de acoplamiento MAPE, lo que claramente indican es que si hay una interacción con los grupos funcionales de la harina de madera. En el caso del tratamiento con el silano VTMS, el grupo funcional posiblemente se ancló a los grupos hidroxilo de la harina mientras que la parte orgánica del silano (grupo vinilo) se unió al adhesivo PU debido a la afinidad química, como tal se logró un incremento de la fuerza adhesiva en 49,7\% y del 8,7 \% en el WPC con 8,0 phr de MAPE (ver Tabla 4). Si la cantidad de harina aumenta en el compuesto es posible que la fuerza adhesiva logre aumentarse. Este resultado es muy similar al tratar químicamente los substratos con el primer Primer $94^{\circledR}$ fabricado por $3 \mathrm{M}^{\mathrm{TM}}$.

Finalmente a nivel de laboratorio se preparó un primer disolviendo el vulcanizante $A Q 212^{\circledR}$ en MEK, hay que recordar que esta sustancia es un toluen diisocianato cuya función primordial es la de entrecruzar el adhesivo de PU para mejorar la resistencia química y térmica del adhesivo, desde luego, el adhesivo en mención se preparó con el vulcanizante antes de ser aplicado. Sin embargo el vulcanizante es un compuesto que tiene alta concentración de grupos funcionales, por esta razón se intentó aprovecharlo como primer y verificar su desempeño. En realidad si mejoró la resistencia al pelado en $24,7 \%$ únicamente para la junta adhesiva formada por substratos sin MAPE (ver Tabla 4 y Figura 2).

\section{Adhesión con hot melt}

El mayor valor de resistencia al pelado se logró en juntas adhesivas unidas por medio de hot melt base EVA con tratamiento de abrasión únicamente. Los valores hallados tanto para los substratos sin MAPE y con 8 phr de agente fueron respectivamente $120 \%$ y $130 \%$ más altos con respecto a substratos iguales unidos con adhesivo PU base agua (ver Tabla 4 y Figura 2). El hot melt se aplicó obviamente en estado fundido, por consiguiente logró humectar la superficie de los substratos debido a la afinidad química que existe entre este tipo de adhesivos y las poliolefinas.

\section{CONCLUSIONES}

La presencia de agentes de acoplamiento tipo copolimeros de maleato en substratos formulados a partir de compuestos de polietileno de baja densidad y harina de madera, los cuales se formulan para mejorar propiedades mecánicas, no afectan el desempeño de la unión adhesiva elaborada con adhesivo tipo hot melt base EVA debido a la afinidad del adhesivo con el polímero.

En caso de que se quiera usar un adhesivo de poliuretano en suspensión acuosa se requiere combinar tratamientos químicos y oxidativos tales como flama, corona y plasma. Los primers pueden mejorar el anclaje del adhesivo con la harina mientras que los tratamientos con gases oxidantes aumentan la energía libre de la poliolefina mejorando la unión del adhesivo con el polímero. Entre mayor sea el contenido de poliolefina en el WPC los tratamientos oxidativos serán más efectivos.

Los silanos son moléculas versátiles y su uso como modificadores de la superficie de WPC con el objetivo de mejorar el anclaje de adhesivos ecológicos de PU quedó demostrada, es importante mencionar que este tratamiento con silano tipo vinílico VTMS fue exitoso siempre y cuando la superficie haya sido lijada previamente con papel abrasivo. Los silanos se preparan en solución acuosa de etanol a diferencia de los primers los cuales en su mayoría son preparados usando solventes tóxicos.

Esta investigación, logró obtener juntas adhesivas de láminas de WPC unidas con adhesivos con baja emisión de volátiles orgánicos (VOC), en reemplazo de los tradicionales cementos base solvente, los cuales tienen buen desempeño pero son peligrosos para la salud humana. El procedimiento aplicado en esta investigación es realmente sencillo y puede ser puesto en práctica con relativa facilidad.

Los compuestos tipo WPC de polietileno con harina vegetal, denominados también como madera plástica se puede transformar por medio de inyección en láminas, cintas o accesorios para la industria del hogar y calzado. Además se pueden obtener perfiles por medio de extrusión para la industria de la construcción. Por tanto es necesario garantizar una adecuada adhesión de los WPC a distintos substratos según el campo de aplicación. 


\section{AGRADECIMIENTOS}

Producto derivado del proyecto INV-ING-1902 financiado por la Vicerrectoría de Investigaciones de la Universidad Militar Nueva Granada, UMNG-Vigencia 2015.

\section{REFERENCIAS}

Abel, M., Handbook of Adhesion Technology, $1^{\text {a }}$ edición, 237-260, Springer, Berlin, Alemania (2011)

Adderley, C.S., Adhesive Bonding, Mater. Design, 9(5), 287-293 (1998)

Critchlow, G., Handbook of Adhesion Technology, $1^{\mathrm{a}}$ edición, 119-146, Springer, Berlin, Alemania (2011)

Davis, G., Handbook of Adhesion Technology, 1를 edición, 147-178, Springer, Berlin, Alemania (2011)

Dimitriou, A., Hale, M.D., Spear, M.J., The effect of four methods of surface activation for improved adhesion of wood polymer composites (WPCs), doi: 10.1016/j.ijadhadh.2016.03.003, Int. J. Adhes. Adhes, 68, 188194 (2016)

Gardner, D.J., Han, Y., Wang, L., Wood Plastic Composite Technology, doi: 10.1007/s40725-015-0016-6. Curr. Forestry Rep., (en línea), (2015)

Günter R., Handbook of Adhesion Technology, 1aㅡ edición, 94-102, Springer, Berlin, Alemania (2011)

Gupta, B.S., Reiniati, I., Laborie, M., Surface properties and adhesion of wood fiber reinforced thermoplastic composites, Colloid Surfaces A, (en línea), 302(1-3), 388-395 (2007)

Haftkhani, A., Ebrahimi, G., Tajvidi, M., Layeghy, M., Arabi, M., Lateral resistance of joints made with various screws in commercial wood plastic composites, doi: 10.1016/j.matdes.2011.03.020, Mater. Design, (en línea), 32(7), 4062-4068 (2011)

Humar, M., Pavlic, M., Zlindra, D., Tomazic, M., Petric, M., Performance of waterborne acrylic surface coatings on wood impregnated with Cu-ethanolamine preservatives, doi: 10.1007/s12034-011-0052-1, B. Mater. Sci., (en línea), 34(1), 113-119 (2011)

Kim, J.K., Pal, K., Recent Advances in the Processing of Wood-Plastic Composites, doi: 10.1007/978-3-64214877-4_2, Eng. Mater, (en línea), 23-35 (2010)

Lei, L., Xia, Z., Ou, C., Zhang, L., Progress in Organic Coatings Effects of crosslinking on adhesion behavior of waterborne polyurethane ink binder, doi: 10.1016/j.porgcoat.2015.07.002, Prog. Org. Coat., (en línea), 88, 155-163 (2015)

Moghadamzadeh, H., Rahimi, H., Asadollahzadeh, M., Hemmati, A., Surface treatment of wood polymer composites for adhesive bonding, doi: 10.1016/j.ijadhadh.2011.08.001, Int. J. Adhes. Adhes., (en línea), 31(8), 816-821 (2011)

Mulonda, K., Preparation and Characterization of Waterborne Polyurethane Crosslinked by Urea Bridges, doi: 10.5539/ijc.v3n2p88, Int. J. Chem., (en línea), 3(2), 88-96 (2011)

Oporto, G., Gardner, D., Bernhardt, G., Neivandt, D., Characterizing the mechanism of improved adhesion of modified wood plastic composite (WPC) surfaces, doi: 10.1163/156856107782105954, J. Adhes. Sci. Technol., (en línea), 21(11), 1097-1116 (2007)

Oporto, G., Gardner, D., Lopez-Anido, R., Interlaminar fracture mechanics applied to bonded wood plastic composites (WPCs) and hybrid WPC- fiber reinforced plastic composites, Proceedings of the International Convention of Society of Wood Science and Technology and United Nations Economic Commission for Europe, Timber Committee, Geneva, Switzerland (2010)

Palacio, O., Buitrago, O., Delgado, A., Evaluación de Polietileno Maleatado en Compuestos de Etil Vinil Acetato y Harina Telinne Monspessulana, doi: 10.4067/S0718-07642016000100015, Inf. Tec., (en línea), 27(1), 139-146 (2016)

Papon, E., Handbook of Adhesion Technology, 1르 edición, 315-340, Springer, Berlin, Alemania (2011)

Rahman, M., Kim, E., Kwon, J., Yoo, H., Cross-linking reaction of waterborne polyurethane adhesives containing different amount of ionic groups with hexamethoxymethyl melamine, doi: 10.1016/j.ijadhadh.2007.03.004, Int. J. of Adhesion and Adhesives, (en línea), 28(1-2), 47-54 (2008)

Yáñez, A.J., Martín, J.M., Incidence of wood content on the surface modifications and adhesion of wood plastic composites (WPCs) treated with oxygen-argon low pressure plasma, EURADH, Alicante, España (2012) 